\title{
O impacto da educação e do trabalho como programas de reinserção social na política de execução penal do Rio de Janeiro*
}

\author{
Elionaldo Fernandes Julião
}

Universidade Federal Fluminense - Instituto de Educação de Angra dos Reis

\section{Introdução}

Diversos países da América Latina, dentre eles o Brasil, vêm apresentando, nos últimos anos, altas taxas de encarceramento. O número cada vez maior de indivíduos reclusos tem sido acompanhado de um crescente sucateamento do sistema prisional, o que prejudica sensivelmente as condições mínimas adequadas para atender aos requisitos da tutela de presos ou de cumprimento de penas nos termos das exigências legais e estabelecidas em convenções internacionais.

O sistema penitenciário assenta-se sobre a punição como forma real e simbólica de solução do problema, propondo, em tese, a ressocialização dos detentos, porque supõe que o "desrespeito" às normas esteja relacionado a uma falta de disciplina moral para o convívio em sociedade. Como se vê, a pena é

* Extraído da tese de doutoramento A ressocialização através do estudo e do trabalho no sistema penitenciário brasileiro, defendida em agosto de 2010 no Programa de Pós-Graduação em Ciências Sociais da Universidade do Estado do Rio de Janeiro (UERJ), sob a orientação de Ignácio Cano. percebida não apenas como punição, mas como fator de reeducação do transgressor.

A partir do século XIX, além dos objetivos de punir o delinquente e defender a sociedade dele, isolando-o para evitar o contágio do mal e inspirando o temor ao seu destino, a meta de reabilitar passou a merecer ênfase especial. Ora sendo vista como semelhante à finalidade do hospital, ora como a da escola, a função da prisão passa a ser designada por terapêutica, cura, recuperação, ato regenerativo, readaptação, ressocialização, reeducação (Foucault, 2000, p. 16).

As Regras Mínimas para Tratamento dos Reclusos, aprovadas pelo Conselho de Defesa Social e Econômica da Organização das Nações Unidas (ONU) em 1955, pelo menos no terreno programático, propõem a finalidade precípua da penitenciária: utilizar a assistência educacional, moral e espiritual no tratamento necessitado pelo interno, de modo que lhe assegure que, no retorno à comunidade livre, esteja apto a obedecer às leis.

Analisando a Lei de Execução Penal (LEP) e o Código Penal dos Países do Ocidente, bem como o discurso prisional predominante, podemos supor que 
o objetivo de recuperação é primordial, ainda que não se abandone a meta punitiva. Examinando, entretanto, os procedimentos disciplinares e pedagógicos dos presídios, evidencia-se a incompatibilidade entre os dois tipos de atribuições penitenciárias. Para Foucault (idem, p. 20), "as prisões não se destinam a sancionar a infração, mas a controlar o indivíduo, a neutralizar a sua periculosidade, a modificar as suas disposições criminosas".

Thompson (1980, p. 13), em seu estudo sobre a questão penitenciária, acredita que "se a adaptação à prisão não significa adaptação à vida livre, há fortes indícios de que a adaptação à prisão implica desadaptação à vida livre".

Sensíveis a uma análise científica profunda, tais objetivos, punição e ressocialização, explicitados como finalidades do sistema penitenciário nas sociedades contemporâneas, são passíveis de críticas e caracterizam-se por ações e metas completamente antagônicas, devido à impossibilidade de recuperarse punindo.

Seja no Rio de Janeiro, em Nova York, Paris, Buenos Aires ou Cingapura, deve-se convir que o interno penitenciário é, em sua grande maioria, excluído de direitos sociais relevantes. Neste sentido, segundo a corrente teórica fundamentada na Criminologia Crítica, ${ }^{1}$ parece correto supor que o sistema penal foi instituído socialmente com o objetivo de aprisionar as mazelas sociais, escamoteando as chagas abertas pela exclusão e pela ganância por poder geradas pelas lutas de classes. Conforme afirma Wacquant (2001), em detrimento de uma política social investe-se demasiadamente em uma política de execução penal.

Nos últimos tempos, o Sistema Penitenciário tem sido percebido como uma caixa-preta: muito se discute, porém pouco se sabe sobre a sua verdadeira realidade. Cada vez mais se constata a necessidade de ampliar a discussão e a pesquisa sobre o tema, dando

${ }^{1}$ A criminologia crítica tem por propósito o estudo do crime e seu controle, assentados na estrutura das classes sociais. Usando do método dialético, aponta as desigualdades econômicas e outras mazelas sociais na origem e persecução da conduta criminosa. ênfase a abordagens interdisciplinares nas universidades e nos institutos de pesquisas, a fim de possibilitar subsídios concretos que contribuam para a constituição de um corpo teórico que subsidie propostas de intervenção nas unidades prisionais para formuladores de políticas públicas.

Foi a isso que se dedicou esta pesquisa, fruto de quatro anos de efetivo trabalho no sistema penitenciário do Rio de Janeiro. Partindo das premissas de educação e profissionalização do apenado como possíveis condições para o seu (re)ingresso no mundo do trabalho e, consequentemente, no convívio social, identifiquei a necessidade de serem envidados esforços em estudos específicos que ofereçam novos encaminhamentos à questão, articulando subsídios intelectuais e técnicos que viessem alicerçar o trabalho prático em andamento nas unidades prisionais, bem como possibilitassem subsidiar políticas públicas para a área. Para isso, foram investigados programas educacionais e laborativos desenvolvidos como política de execução penal no Brasil, principalmente do Rio de Janeiro, buscando verificar qual o real impacto da educação e do trabalho na reinserção social do apenado.

O presente artigo apresenta parte dos resultados de minha tese de doutoramento, cujo objetivo foi descrever e analisar as relações entre educação escolar, trabalho e ressocialização em um sistema penal e a efetividade dessas ações.

\section{Reflexões sobre o papel das políticas de execução penal nas sociedades ocidentais}

$\mathrm{Na}$ história da penalogia moderna e dos estudos criminológicos no mundo ocidental em fins do século XVIII e começo do XIX, como resultado das ideias iluministas que ao mesmo tempo em que elegem a liberdade como um bem maior, criticam os procedimentos punitivos medievais, segundo Foucault (2000), caminhamos em uma perspectiva de nova era na justiça penal.

Entre tantas modificações, a principal foi o desaparecimento dos suplícios. A punição deixa o campo da 
percepção e entra no da consciência abstrata, tornandose a parte mais velada do processo penal. A certeza de ser punido é que deve passar a desviar o homem do crime e não mais o seu abominável espetáculo. Entramos em uma perspectiva da penalidade incorpórea. Deixa-se de ferir o corpo e passa-se a atingir a alma. A privação de liberdade, desta forma, passaria a ser uma punição reconhecida como produtora de dor moral.

Sob o discurso de humanização da pena, são criadas instituições de controle social, com o objetivo de aprisionar aqueles que cometeram alguma infração. $\mathrm{O}$ espetáculo público da expiação, gerado pela cerimônia penal, sai de cena e entra o do encarceramento. A sociedade não mais presencia tal espetáculo; o infrator, separado em locais de prisão, torna-se inacessível ao público. ${ }^{2}$

Com a reforma, agregam-se à ideia de punição os conceitos de reinserção, reabilitação social, ressocialização. Assim, a punição passa não só a se destinar a sancionar a infração, mas a controlar o indivíduo, a neutralizar a sua periculosidade, a modificar suas disposições criminosas, cessando somente após obtenção de tais modificações (Foucault, 2000, p. 20).

Com a nova ordem social instaurada, com a regularização de um Direito Judiciário pautado não mais no suplício do corpo do infrator, mas sim em uma perspectiva de reincorporação do delinquente à sociedade, toda legislação penal foi reformulada: são criadas as chamadas Casas de Correção. ${ }^{3}$ A administração da execução penal, por efeito dessa nova retenção, agora é composta por um exército de técnicos que substituem

${ }^{2}$ A pena de morte, ainda hoje executada em algumas regiões, demonstra que a perspectiva de punição não avançou em todo o mundo.

3 Segundo Lúcia Guimarães, no Brasil, por exemplo, na década de 1830, iniciou-se um levante popular dirigido pela Sociedade Defensora da Liberdade e da Independência Nacional, que, em resposta ao clima de violência que estaria envolvendo a cidade, lançou uma campanha para a construção do primeiro presídio do Rio de Janeiro, a Casa de Correção que deu origem ao antigo e desativado Complexo Penitenciário Frei Caneca, situado no centro do Rio de Janeiro (Julião, 2003). a figura do carrasco, figura que simboliza a autoridade de execução nas sentenças de morte.

A finalidade da pena privativa de liberdade passa a ter a obtenção de vários objetivos conjuntos; a meta de reabilitar, porém, passou a obter ênfase especial a partir do século XIX: ${ }^{4}$

\section{Convertida no centro irradiador do sistema penitenciário, na própria medida em que a pena privativa de liberdade constitui o essencial, a prisão assume uma tripla função: punir, defender a sociedade isolando o malfeitor para evitar o contágio do mal e inspirando o temor ao seu destino, corrigir o culpado para reintegrá-lo à sociedade no nível social que lhe é próprio. (Perrot, 1988 apud Breitman, 1989, p. 194)}

Com a crescente onda de violência que vem assolando o espaço urbano, constantes movimentos de reflexão discutem o real papel do sistema penitenciário em pleno século XXI. Uns, acreditando que a severidade da pena imposta é preventiva, investem na reformulação da atual legislação, acreditando na instituição de leis mais severas. Outros, descrentes de que a severidade da pena imposta tenha eficácia preventiva ou reabilitadora, discutem a necessidade de criação de meios e métodos alternativos ao simples encarceramento, fundamentados nas ideias do jurista italiano do século XVIII Cesare Becaria ${ }^{5}$ (2000), defensor da tese de que o que inibe o crime não é o tamanho da pena, mas a certeza da punição, e de Jeremy Bentham ${ }^{6}$ (2000), que defende que essas instituições devam ser simplesmente seguras e capazes de isolar os delinquentes tanto da sociedade quanto

\footnotetext{
${ }^{4}$ Thompson (2007) chama nossa atenção para o fato de
} que oficialmente tem prevalência o alvo recuperação, mas não se autoriza que seja obtido à custa do sacrifício dos objetivos punição e intimidação.

5 Influenciado pelas ideias iluministas, principalmente as propostas por Rousseau, Montesquieu e Diderot, no pensamento criminológico e penalista de então.

${ }^{6}$ Importante teórico da prisão moderna e que estabelece os princípios da racionalização da instituição prisional a começar por sua arquitetura. 
uns dos outros. Para eles, a criminalidade nunca foi resolvida com a repressão dura. A pena de reclusão está superada como forma de reeducação.

As referidas discussões fundamentam-se em orientações internacionais de duas correntes filosóficas. A primeira pautada nas ideias norte-americanas, principalmente nas instituídas pelo estado de Nova York, a da tolerância zero, ${ }^{7}$ que sustenta o conceito de que é lutando contra os pequenos distúrbios cotidianos que se faz recuar as grandes patologias criminais. A segunda, preocupada com as questões sociais que envolvem a delinquência, prega uma justiça social, não valorizando a pena privativa de liberdade, mas sim meios e métodos alternativos ao encarceramento. Privilegia a ideia de que tal pena é a última instância para o delinquente, sendo, portanto, só cabível aos casos em que o infrator signifique risco concreto à vida da comunidade.

Uma terceira corrente vem crescendo, nas últimas décadas, com muita força, à margem dessas duas, principalmente em alguns países da América Latina, como Argentina, Chile, Colômbia e México, defendendo um Direito Alternativo e repudiando a visão tradicional positivista acrítica do Direito, cuja racionalidade se centra em começar e findar na lei.

A criminologia do século XXI está efetivamente pautada em duas concepções opostas de cárcere, gerando políticas públicas de segurança carcerária também contrastantes: uma, fundamentada na criminologia clínica tradicional, ${ }^{8}$ de cunho positivista; outra

${ }^{7}$ Centrada na teoria dita da vidraça quebrada formulada por James Q. Wilson e George Kelling: adaptação do ditado popular quem rouba um ovo, rouba um boi. Loïc Wacquant (2001a, p. 25), um dos maiores críticos dessa corrente, denuncia que buscam apoio nas instituições policial e penitenciária a fim de conter as desordens geradas pelo desemprego em massa, a imposição do trabalho assalariado precário e a retração da proteção social, restabelecendo uma verdadeira ditadura sobre os pobres.

${ }^{8}$ Compreende haver no indivíduo criminoso uma condição de periculosidade. O cárcere será ideal quanto mais ele for capaz de conter essa periculosidade. Tem como meta prioritária conter o delinquente, mantendo-o segregado da sociedade. baseada nos pressupostos da Criminologia Crítica. ${ }^{9}$ Assim, enquanto a tradicional se fundamenta no dilema da prioridade da segurança, paradigma estritamente coercitivo, a crítica fundamenta-se na prioridade da individualização da execução da pena, no paradigma da segurança humanista. Nessa perspectiva, a primeira orienta-se pelo interesse e bem-estar da sociedade e do sistema, ao passo que a outra, pelo interesse e bemestar da população carcerária. Em síntese, estamos diante de dois grandes parâmetros filosóficos para uma política legislativa e de execução penal, um centrado na valorização da responsabilidade individual sobre o fato social e outro, oposto, priorizando o indivíduo nas suas relações histórico-sociais.

Partindo do pressuposto de que não há crime sem lei anterior que o defina, pode-se perceber que as leis são construções sociais e como tais devem ser consideradas, e que as diferenças na capacidade de fazer regras e aplicá-las a outras pessoas representam essencialmente diferenças de poder. Aqueles grupos cuja posição social lhes confere poder são mais capazes na imposição de suas regras.

Seguindo um movimento real de criminalização dos pobres, ${ }^{10}$ pelo menos no âmbito teórico ou discursivo o poder público proclama a instituição ou valorização de uma política de execução penal pautada sob a égide dos Direitos Humanos, em que se prima pelo direito à condição humana sobre todas as coisas. Por sua vez, conforme a visão do poder, a política penitenciária implementada pelo Poder Executivo tem como objetivo central proteger a sociedade.

Diante de uma análise mais apurada dos fatos, percebe-se que todo o investimento para a política de execução penal, contrariamente ao discurso predominante, está calcado na valorização de propostas

9 Compreende haver na pessoa encarcerada, decorrente da condição de exclusão e segregação sociais, uma condição de vulnerabilidade. Defendem a promoção da cidadania, independentemente da necessidade da flexibilização das regras de contenção do cárcere.

10 Tese veementemente defendida pelo sociólogo Löic Wacquant. 
políticas que viabilizem uma possível proteção da sociedade sobre todas as coisas, ficando em segundo plano a implementação de ações concretas que propiciem melhor condição ao delinquente no espaço carcerário. Investe-se na construção de novos presídios cada vez mais bem aparelhados, dispostos para impedir o contato do apenado com a sociedade. Ao se analisarem as unidades visitadas em vários estados brasileiros, em países da América Latina e Europa são dispensados espaços adequados de atendimento biopsicossocial, bem como educativos, esportivos e culturais em prol da segurança.

Com uma demanda crescente de unidades prisionais que atendam os objetivos da sociedade, pesados investimentos vêm sendo feitos na construção de novos presídios em todo o país, bem como da desinstalação dos que se localizam nos grandes centros urbanos, transferindo-os para o interior dos estados. ${ }^{11}$ Como se pode observar, tal fato tende diretamente a confirmar a hipótese de que a execução penal não tem mais como objetivo ressocializar o delinquente, mas sim proteger a sociedade desse indivíduo e puni-lo pelo ato cometido.

Diferentemente de toda uma atual proposta política e ideológica que envolve os indivíduos considerados portadores de patologias e distúrbios mentais, primando-se por um movimento antimanicomial, ${ }^{12}$ em que se acredita que, pelo contato direto com a sociedade, os indivíduos chamados "loucos" serão ressocializados, investe-se demasiadamente no afastamento do delinquente de suas possíveis relações sociais, criando-se cadeias públicas e privadas em espaços distantes dos centros urbanos.

${ }^{11}$ Como exemplo, recordamos a desativação de parte do Carandiru, em São Paulo, bem como da desativação do Complexo Penitenciário Frei Caneca, no Rio de Janeiro, transferindo suas unidades para o interior desses estados.

12 Movimento instituído nas últimas décadas que investe na desinstalação dos manicômios e criação de ambulatórios em hospitais para atendimento dos indivíduos portadores de doenças mentais.
[...] a preocupação política dos dias de hoje não é puramente punitiva (tal que pudesse ser satisfeita por medidas como castigo corporal) nem puramente orientada para a proteção pública (o que, antigamente, levava a medidas de detenção preventiva que minimizavam seu conteúdo punitivo). Temse a preocupação de produzir sanções que combinem os dois modos de ver sob a forma de uma segregação e de uma incapacitação punitivas. O novo ideal penal é que o público seja protegido e que seus sentimentos sejam expressos. A segregação punitiva - penas de longa duração em prisões "sem frescuras" e uma existência estigmatizada, controlada de perto, para aqueles que são, finalmente, libertados - é cada vez mais a escolha que se impõe. (Garland, 1999, p. 61, aspas do original)

Analisando este momento histórico mundial conflituoso que se instaura, percebe-se que o Estado vem optando claramente pela criminalização da miséria e o encarceramento maciço como complemento da generalização da insegurança salarial e social. Conforme Wacquant (2001c), socializa-se entre os diversos países em diferentes continentes, internacionalizando-se paralelamente à ideologia econômica neoliberal da qual é a tradução em matéria de justiça, uma globalização de políticas e técnicas agressivas de segurança made in USA, importando-se como soluções mágicas para o crucial problema da violência criminal. Para ele, na América Latina ${ }^{13}$ o tratamento policial e judiciário da miséria é essencialmente antitético à consolidação de uma sociedade democrática, uma vez que significaria (r)estabelecer uma verdadeira ditadura sobre os pobres.

Desse modo, percebe-se um movimento real de criminalização dos pobres em que, embora pelo menos no âmbito teórico ou discursivo, o poder público proclama a instituição ou a valorização de uma política

${ }^{13}$ A criminalização da pobreza, em linhas gerais, também é vista como uma tese muito centrada nos Estados Unidos da América e na Europa Ocidental e vincula o encolhimento do Estado de bem-estar social ao endurecimento penal. Na América Latina, ao contrário, onde o Estado de bem-estar social nunca existiu, a vinculação de ambos os processos é questionável. 
de segurança pública pautada nos Direitos Humanos, valorizando, acima de tudo, o direito à condição humana; em contrapartida, com medidas de exceção, a política implementada tem como objetivo central proteger uma camada da sociedade, deixando de lado os direitos individuais fundamentais.

Em recente pesquisa realizada pela socióloga Laura Frade (2007), sobre um levantamento que mostra as proposições parlamentares relacionadas ao crime apresentadas entre 2003 e o começo de 2008 no Congresso Brasileiro, vê-se que, das 646 proposições parlamentares, a quase totalidade se destinava a agravar penas e somente duas se relacionavam a crimes de corrupção perpetrados por não pobres, popularmente conhecidos como "crimes de colarinho branco". No estudo, a autora ressalta que apenas 7\% das matérias do Legislativo tratam do tema criminalidade, demonstrando não ser o combate ao crime um tema prioritário no Congresso Brasileiro.

No Brasil, toda a discussão em voga no momento sobre a constitucionalidade do crime denominado hediondo, bem como sua ampliação em relação aos crimes que vêm crescendo no país, em parte se justifica com base em uma racionalidade econômica. Muitos alegam que é por conta da atual estrutura legislativa sobre a caracterização dos crimes hediondos que se vêm superlotando as prisões. $\mathrm{O}$ aspecto econômico e financeiro, na maioria dos casos, tem sido constantemente enaltecido na discussão, deixando-se de lado todo o aspecto ideológico e social que caracteriza o tema.

Conforme já denunciara Foucault (2000), a reforma do Direito Judiciário nunca teve o objetivo de fundar um novo direito de punir, mas de estabelecer uma nova economia do poder de castigar. A reforma do Direito Criminal, segundo ele, é uma estratégia para o remanejamento do poder de punir, seguindo modalidades que aumentem os efeitos, diminuindo o custo econômico.

Segundo Garland (1999, p. 70), “o investimento da criminalidade e os dispositivos de segurança são, portanto, cada vez mais impostos antes pelas forças econômicas do que pela política pública". Pautado sobre a ideia das novas criminologias da vida cotidiana, afirma que, não se dando mais ao trabalho de se empenhar na reabilitação dos delinquentes, "as autoridades carcerárias insistem cada vez mais na sua capacidade de ministrar castigos e proteger o público pelo simples fato de trancafiar os delinquentes na prisão" (idem, p 66). E que os programas terapêuticos e de reinserção já não são sustentados pela ideologia geral do sistema. Segundo esse autor, para este novo modelo que se instaura, o crime é um acontecimento que não requer nenhuma motivação ou disposição especial, nenhuma patologia ou anormalidade, e que se inscreve nas rotinas da vida econômica e social contemporâneas.

Podemos concluir, com Wacquant (2001, p. 86), que:

\footnotetext{
Essa mudança de objetivo e de resultado traduz o abandono do ideal de reabilitação [...] cujo objetivo não é mais nem prevenir o crime, nem tratar os delinquentes visando o seu eventual retorno à sociedade uma vez a pena cumprida, mas isolar grupos considerados perigosos e neutralizar seus membros mais disruptivos mediante uma série padronizada de comportamentos e uma gestão aleatória dos riscos, que se parecem mais com uma investigação operacional ou reciclagem de detritos sociais que com trabalho social
}

Nesse sentido, o ambiente prisional será, por definição, refratário a quaisquer práticas pedagógicas que intentem a condução dos internos à vida em liberdade. Temos apenas uma espécie de silo de exclusão.

\section{A pesquisa}

Seguindo Thompson (1980, p. 21-22), compreendo que "o significado da vida carcerária não se resume a mera questão de muros e grades, de celas e trancas; ele deve ser buscado através da consideração de que a penitenciária é uma sociedade dentro de uma sociedade, uma vez que nela foram alteradas, drasticamente, numerosas feições da comunidade livre" e que, como um sistema social, a penitenciária representa uma "tentativa de criação e manutenção 
de um grupamento humano submetido a um regime de controle total". Em consequência, tomando como referência o microcosmo social objeto de análise, a pesquisa realizada pretendeu apreender a realidade sobre o sistema penitenciário em sua multiplicidade de facetas, em diversos planos e dimensões, possibilitando uma reconstrução sociológica do problema.

Em virtude das dimensões territoriais do Brasil e da sua proposta política de execução penal, tomou-se como recorte de trabalho o estado do Rio de Janeiro - terceiro estado que mais encarcera em número absoluto no país. ${ }^{14}$ Foram utilizadas na pesquisa informações gerais sobre o sistema penitenciário estadual, além de informações do banco de dados da Vara de Execuções Penais (VEP), ${ }^{15}$ e entrevistados profissionais de diversas unidades penais do estado e internos penitenciários do Complexo de Gericinó, localizado em Bangu, Zona Oeste da capital. ${ }^{16}$

Para responder às indagações propostas, procurou-se identificar, entre outras questões: o perfil do interno no estado do Rio de Janeiro; os principais programas de ressocialização desenvolvidos; a participação dos internos nesses programas, principalmente nas atividades laborativas e educacionais; a taxa de reincidência; a taxa, a probabilidade e as chances de reincidência entre apenados e egressos que participaram ou não dessas atividades.

Além do trabalho de coleta e interpretação de dados quantitativos, buscou-se, por meio de entrevistas, captar o discurso dos diversos agentes envolvidos na política pública de execução penal, com o objetivo de compreender, a partir da perspectiva destes atores, como vêm sendo desenvolvidos programas de ressocialização na política de execução penal. Como parte

${ }^{14} \mathrm{O}$ Rio de Janeiro, segundo dados da Secretaria de Estado de Administração Penitenciária do Rio de Janeiro - SEAP, em 2009, encarcera mais de 28 mil pessoas, cerca de $7 \%$ da população prisional do país, estando somente atrás de São Paulo e Minas Gerais.

${ }^{15}$ Sistema de Informação Penitenciária da Vara de Execuções Penais do Rio de Janeiro (SIPEN/VEP).

${ }^{16}$ Região que concentra o maior número de unidades penais no estado. das técnicas de investigação adotadas na pesquisa, as entrevistas seguiram um roteiro de questões previamente definidas. Também foram aplicados questionários com perguntas fechadas e abertas. Procurou-se ainda identificar a relação da percepção dos diversos agentes operadores da execução penal com os dados objetivos coletados no banco de dados da Vara de Execuções Penais.

Todas as etapas deste estudo foram registradas em um caderno de observações de campo, inclusive conteúdos e impressões obtidas em cada reunião ou encontro, utilizando-se esses apontamentos objeto de análise, na medida em que conferiram significado às discussões do estudo.

\section{Estratégia de análise do material empírico}

As entrevistas semiestruturadas privilegiaram a discussão sobre os diversos aspectos que envolvem os programas de ressocialização tanto no campo teórico quanto prático da execução penal. Foram realizadas sete entrevistas com os principais agentes operadores da execução penal no estado e com coordenadores dos programas de ressocialização da Secretaria de Estado de Administração Penitenciária.

Optei por não realizar entrevistas com o secretário de Administração Penitenciária, acreditando que, em virtude do perfil político do cargo, as respostas não contribuiriam diretamente para o objetivo da pesquisa.

Seguindo o roteiro de entrevistas, produziu-se um questionário com perguntas abertas e fechadas que foi aplicado a outro grupo de agentes operadores da execução penal no estado do Rio de Janeiro (agentes penitenciários, chefes de segurança e profissionais da equipe técnica). Nessa etapa, foram aplicados cerca de 310 questionários, porém somente oitenta, isto é, $25 \%$ do total, foram respondidos.

Procurando verificar a percepção dos internos quanto ao papel do trabalho e da educação como programas de reinserção social, foram realizadas também 65 entrevistas com internos do sexo masculino da Penitenciária Esmeraldino Bandeira, da Casa de 
Custódia Elizabeth Sá Rêgo (Bangu V) e do Instituto Penal Plácido de Sá Carvalho.

A escolha das unidades prisionais levou em consideração os regimes fechado, semiaberto, aberto e provisório; a existência de escolas regulares e espaços com oficinas de trabalho; bem como a filiação, em tese, dos internos a determinadas facções. ${ }^{17} \mathrm{Em}$ cada unidade, procurei realizar o mesmo número de entrevistas com internos que estudavam e trabalhavam e que não estudavam nem trabalhavam. Poucos foram os casos de entrevistados que diziam realizar as duas atividades. Em nenhuma unidade entrevistei um único segmento (estudantes, não estudantes; trabalhadores e não trabalhadores).

Embora estivesse prevista inicialmente a realização do mesmo número de entrevistas com egressos do sistema, em virtude das dificuldades encontradas, principalmente de ex-internos dispostos a falar sobre o tema, só foi possível entrevistar três pessoas, número que não pode ser considerado representativo. Para minimamente se alcançar tal objetivo, foram realizadas entrevistas com internos da Unidade Plácido de Sá Carvalho, que, em tese, abriga grande número de internos em regime semiaberto, ou seja, que somente são obrigados a dormir na unidade, caso desenvolvam oficialmente atividades laborativas e educacionais extramuros.

A dinâmica de escolha dos internos que dariam a entrevista observou as especificidades de cada unidade. A participação foi voluntária, respeitando sempre $o$ interesse em ser entrevistado.

As entrevistas foram realizadas obedecendo a um padrão técnico, seguindo o roteiro básico, a fim de oferecer mecanismos e subsídios para análise temática do conteúdo das falas dos principais sujeitos envol-

${ }^{17}$ É sabido que a criminalidade do Rio de Janeiro se articula, basicamente, nas facções Terceiro Comando e Amigo dos Amigos, facções cujos membros apenados são internos na Unidade Plácido de Sá Carvalho. Os do Comando Vermelho são alocados em Bangu V. Já a Unidade Esmeraldino Bandeira é considerada "neutra", apesar de possuir alguns integrantes também do Comando Vermelho. vidos na execução penal no estado do Rio de Janeiro. Todas foram gravadas em fita cassete. Para a análise do questionário aplicado, foi produzido um banco de dados; no cruzamento das informações geradas foram utilizados os mesmos "eixos temáticos" ou categorias das entrevistas semiestruturadas.

Já com relação à análise do banco de dados da VEP, foi criado um novo banco de dados, a partir das informações do banco primário cedido pelo Tribunal de Justiça. O objetivo da análise e do cruzamento de diversos dados sobre os apenados foi o de verificar, principalmente, possíveis relações existentes entre estudo, trabalho e reincidência (criminal e penitenciária) no sistema penal.

Em virtude da complexidade do tema abordado, defini como principal instrumental teórico para a fundamentação e análise do material coletado algumas questões da literatura especializada sobre o tema políticas de execução penal e sobre categorias usadas neste estudo, a saber: ressocialização, reincidência, estigma, prisonização, punição, sociedade punitiva, privação de liberdade, educação de jovens e adultos e outros.

Também foram utilizados os pressupostos teóricometodológicos das ciências sociais, principalmente os desenvolvidos por Howard Becker sobre o interacionismo simbólico e sobre as questões que envolvem o comportamento desviante e a percepção do desvio como decorrência de um processo de acusação e por Erving Goffman (1961 e 1988) sobre instituições totais e estigma. Além desses teóricos, foram usados modernos estudos sobre crime e punição dos autores Loïc Wacquant (2001a, b e c), que defende a tese da “criminalização da miséria e punição dos pobres"; David Garland (1990), sobre "punição e sociedade moderna" e "contradições da sociedade punitiva"; Nils Christie (1993), sobre "a cultura do controle do delito", e Eugenio Raúl Zaffaroni (2001), sobre "a perda da legitimidade do sistema penal". Já no campo da educação, foi privilegiado o diálogo como alguns estudos sobre políticas públicas e educação para jovens e adultos, principalmente dialogando com alguns escritos de Jane Paiva (2009), Leôncio Soares (2002) e outros. 


\section{Algumas descobertas da pesquisa}

Em virtude da impossibilidade de serem resgatadas todas as questões debatidas na tese de doutoramento, serão destacadas algumas neste artigo, consideradas especiais em todo o processo de construção e descobertas.

Amparado nas hipóteses que orientaram a pesquisa, dentro de um elenco de questões suscitadas pelos entrevistados, bem como dos dados analisados do Banco de Dados da Vara de Execuções Penais, foi possível evidenciar, dentre outras questões, por exemplo, que da discussão que assegura ao infrator a condição de sujeito perante o aparato judicial, considerando-o sujeito de direitos e de responsabilidades e como pessoa em condição de desenvolvimento (Doutrina da Proteção Integral), negando a postura que considera o delito manifestação patológica (Doutrina da Situação Irregular), emerge uma concepção de política de execução penal pautada em uma ideia moderna de "tratamento penitenciário".

Essa concepção implica e requer um conjunto articulado de ações por parte do Estado e da sociedade, para a garantia de direitos fundamentais básicos (como o direito à sobrevivência, o direito ao desenvolvimento pessoal e social, além do direito à integridade física, psicológica e moral) por meio de políticas sociais básicas (saúde, trabalho e educação), políticas de assistência social, políticas de proteção especial e políticas de garantia de direitos. Diante dessas questões, é necessário colocar em prática o princípio de que o indivíduo privado de liberdade está, de fato, privado de direito de ir e vir, detendo ainda liberdade de consciência, de expressão, de religião e de criação.

Quanto à compreensão dos diferentes agentes operadores da execução penal sobre o conceito ressocialização para a pesquisa, pode-se dizer que para eles, em síntese, isso significa o indivíduo "voltar à sociedade adaptado, respeitando as leis". Ou seja, “o preso deve voltar para a sociedade sem delinquir". No entanto, diante das questões explicitadas, defendo a ideia de que os conceitos ressocialização e reinserção social (impregnados da concepção político pedagó- gica de execução penal que compreende o cárcere como "instituição total"/“instituição completa", em que o indivíduo é capturado da sociedade, segregado totalmente da comunidade livre) estão ultrapassados, devendo ser substituídos por "socialização". Com essa nova concepção, compreende-se o sistema penitenciário com uma instituição social como tantas outras, reconhecendo a sua incompletude (tanto institucional, quanto profissional), cria-se uma nova dinâmica política e ideológica que prima pela não segregação total do indivíduo, pela concepção de que o ser humano vive em um constante processo de socialização e reconhece-se que o papel do sistema de privação de liberdade, em suma, é de "socioeducar": do compromisso com a segurança da sociedade e de promover a educação do delinquente para o convívio social.

Quanto às principais questões evidenciadas pelos agentes operadores da execução penal no debate sobre o trabalho e a educação em espaços de privação de liberdade, todos reconhecem a importância do trabalho e da educação no cárcere; porém, uns valorizam a educação em detrimento do trabalho e vice-versa; outros não acreditam na existência de grau de prioridade, mas sim na necessidade de se organizar uma proposta política em que todos devam estudar e, consequentemente, serem preparados para o trabalho, articulando-se o estudo ao trabalho.

Também entre os internos entrevistados não foi possível encontrar uma unanimidade quanto ao tema trabalho no sistema penitenciário; alguns concordam que é importante trabalhar no cárcere, outros discordam por motivos diversos, alegando, inclusive, que a legislação penal brasileira determina que o trabalho deve ter um cunho educativo. Outros chegam a alegar que o trabalho intramuros é exploração. Segundo estes, todas as empresas que se utilizam da mão de obra do apenado, mascaradas muitas vezes por uma imagem de ideal filantrópico, têm como objetivo explorar o apenado, ampliando as suas margens de lucro à sua custa.

Com relação ao papel da escola no cárcere, em linhas gerais, também não existe uma unanimidade. A grande maioria a reconhece como um espaço im- 
portante para "passar o tempo", "ocupar a mente" dos internos e possibilitar alguns benefícios, principalmente a remição. Poucos entrevistados, ao contrário, evidenciaram algo positivo, principalmente quanto à possibilidade de auxiliar em sua reinserção social. Assim, percebe-se que muitos internos não têm interesse de estudar porque não conseguem enxergar no estudo algo positivo; não conseguem visualizar as potencialidades da educação para a sua vida, principalmente extramuros.

Quanto à escolha do interno entre estudar e trabalhar, embora a margem de diferença seja muito pequena, a maioria prefere e opta pelo estudo; em segundo lugar o trabalho e, por último, se pudessem conciliar, realizariam os dois. Analisando suas respostas, percebe-se que a opção pelo estudo está relacionada a uma perspectiva de futuro, principalmente quanto à reinserção social. Com relação à escolha do trabalho, as justificativas estão relacionadas a interesses imediatos, principalmente no que diz respeito à aquisição de benefícios no presente: remição de pena, sustento da família, ocupação do tempo etc.

Várias foram as explicações sobre os motivos que levam os internos a não estudar no cárcere. Dentre elas destacam-se: porque se consideram velhos demais para estudar; porque não conseguem conciliar o estudo com outras atividades desenvolvidas na unidade (principalmente o artesanato e as atividades da igreja); porque não têm disposição para se dedicar aos estudos; porque não têm oportunidades, já que a escola é oferecida para alguns, excluindo principalmente os internos que estão no "seguro", ${ }^{18}$ e por inadequação da proposta pedagógica e metodológica da escola. Vale lembrar que, por não existir uma proposta pedagógica para a execução penal nas unidades, muitas são as dificuldades para conciliar a realização de mais de uma atividade no cárcere.

A taxa de reincidência penitenciária no Sistema Penal do Rio de Janeiro estimada na pesquisa, ao

${ }^{18}$ Ambientes reservados no interior das unidades para apenados que, geralmente por questões de segurança, devem permanecer isolados do coletivo. contrário do que comumente é divulgado pela mídia, é de apenas $30 \%$, pois, à medida que o intervalo de tempo da liberdade vai aumentando, cresce linearmente a probabilidade de reincidência. Por volta de cinco anos, essa taxa pode alcançar $30 \%$ dos réus; após cinco anos de liberdade, a taxa de reincidência mantém-se aproximadamente constante.

Diante dos dados levantados na pesquisa, levandose em consideração as diversas ressalvas explicitadas no decorrer da análise, pode-se constatar que realmente é diferente o perfil social dos reincidentes em comparação aos não reincidentes: os reincidentes são, na grande maioria, do sexo masculino, solteiros, jovens, pretos e com uma escolaridade deficiente. Além disso, os dados permitem afirmar que os internos que participam dos projetos educacionais e laborativos apresentam predisposição à ressocialização, assim como também apresentam características distintivas daqueles que não estudam nem trabalham.

O estudo da regressão evidenciou que os fatores que aumentam a reincidência penitenciária são: ser homem; ser jovem; ter cometido os crimes de roubo, furto e estelionato/fraude (em comparação com o tráfico). Além disso, mostrou que para cada ano de liberdade o réu tem mais chances de reincidir e que quem trabalha têm menor chance de reincidir, assim como quem estuda.

Quando comparamos o trabalho ao estudo, evidencia-se que ambos são significativos, porém, enquanto o estudo no cárcere diminui a probabilidade de reincidência em 39\%, o trabalho na prisão diminui essas chances em 48\%. Ou seja, os referidos dados não ratificam uma das hipóteses iniciais desta pesquisa de que o efeito do estudo é superior ao do trabalho na reinserção social do apenado.

$\mathrm{Na}$ análise dos dados referentes aos indivíduos que estudaram e trabalharam no sistema penitenciário fluminense, foi possível verificar que a elevação de escolaridade é inversamente proporcional ao tempo dedicado ao estudo. Ao contrário, o interesse pelo trabalho aumenta com a elevação do nível de escolaridade. Ou seja, quanto mais elevada a formação educacional, menos tempo, por exemplo, foi dedicado 
ao estudo. Em contrapartida, quanto mais elevada a sua formação mais tempo foi dedicado ao trabalho.

Em linhas gerais, como resultado da pesquisa, pode-se afirmar, por um lado, que o trabalho e o estudo representam papel significativo na reinserção social dos apenados, diminuindo consideravelmente sua reincidência; quem tem disposição para se reinserir tem mais predisposição a estudar e trabalhar. Por outro lado, ao contrário do que se imaginava, o efeito da educação é inferior ao do trabalho como programa de reinserção social para a política de execução penal, apresentando dados menos significativos.

Embora os projetos laborativos e educacionais para jovens e adultos privados de liberdade acumulem uma longa história no país, pode-se tacitamente afirmar que ainda não existe uma política pública de educação e de trabalho para o sistema penitenciário e que ainda são ações isoladas (realizadas como projetos) sem a institucionalização de uma proposta político-pedagógica que abarque as características e finalidades de tal realidade, bem como de investimentos e repasses de recursos financeiros.

Dentre os principais problemas identificados em uma avaliação genérica sobre as atividades laborativas e educacionais para jovens e adultos privados de liberdade, destacam-se, por exemplo:

1) ausência de uma diretriz nacional para a política de tratamento penitenciário que oriente minimamente as ações estaduais, assim como o discurso que caracterize o papel da educação e do trabalho como proposta política para o sistema penitenciário, ${ }^{19}$

2) ausência de unidade nas ações educacionais desenvolvidas - porque ainda não se definiram as atribuições dos diversos órgãos envolvidos na política (ministérios, secretarias, superintendências, departamentos etc.). Em virtude

${ }^{19}$ O Ministério da Justiça e o Ministério da Educação vêm realizando nos últimos anos um importante ensaio de implementação de uma proposta interministerial para educação no sistema penitenciário. desta falta de definição das suas atribuições, todos geralmente desenvolvem as mesmas atividades, pulverizando os poucos recursos que lhes são disponíveis;

3) a maior parte das ações educacionais e profissionalizantes são desenvolvidas de forma precária, sem recursos materiais e em espaços improvisados, muitas vezes sem qualquer planejamento prévio, sem uma proposta pedagógica, curricular e metodológica definida para esse trabalho;

4) ausência de informações detalhadas sobre o perfil biopsicossocial dos internos e dos profissionais que atuam no sistema penitenciário, impossibilitando melhor orientação para a implementação de políticas públicas na área;

5) os profissionais que atuam nestas áreas no cárcere não são capacitados para o trabalho; visto a sua especificidade, sequer vivenciam um processo de ambientação e, posteriormente, de formação continuada (não existe uma política de recursos humanos instituída para o sistema penitenciário);

6) e, por fim, ausência de mecanismos de acompanhamento e avaliação de programas e projetos financiados com recursos públicos.

\section{Considerações finais}

É senso comum afirmar que avaliar políticas e programas sociais nos últimos tempos se tornou um desafio tanto para os centros de pesquisa quanto para os governos. Tarefa mais complexa ainda é avaliar políticas e programas sociais desenvolvidos para o sistema penitenciário.

De um modo geral, a sociedade vem reivindicando cada vez mais uma relação de transparência e de participação nas decisões referentes a alternativas políticas e programáticas. Reivindica-se conhecer e acompanhar a equação entre gastos públicos e custo-efetividade de políticas e programas destinados a produzir maior equidade social. Espera-se 
das organizações eficiência, eficácia e equidade na prestação de serviços de interesse do cidadão. Neste sentido, a avaliação, além de permitir aprimorar as ações institucionais, possibilita manter uma relação de transparência com a sociedade no que tange a seus propósitos, processos e resultados, realimentando decisões e opções políticas e programáticas.

Quando pensada para a realidade dos sistemas de privação de liberdade, cujo cotidiano é comumente invisível, percebe-se que, ao contrário do explicitado, a sociedade nunca demonstrou real interesse sobre o que efetivamente ocorre dentro do cárcere ou em uma unidade socioeducativa, sobre a qualidade dos serviços prestados e tampouco sobre investimentos realizados na área etc. Culturalmente, esses sistemas nunca passaram por um processo de avaliação (principalmente de qualidade) que possibilitasse apresentar resultados sobre a sua eficiência, eficácia e efetividade. Os únicos indicadores de qualidade que sempre chamaram atenção da sociedade com relação ao tema são as rebeliões, motins ou fugas. São essas informações, principalmente as negativas, que fazem que a tranquilidade da sociedade venha a ficar abalada. Ao contrário, com poucas exceções, não se evidencia qualquer outro interesse.

No campo das políticas de execução penal, diante da diversidade de fatores que envolvem o tema, é necessário propostas e estratégias específicas de acompanhamento e avaliação, que valorizem concepções mais abrangentes e totalizantes, que busquem apreender a ação, sua formulação, implementação, execução, processos, resultados e impactos. Ou seja, que não só se invista em uma avaliação apenas de resultados, que mensure quantitativamente os benefícios e malefícios de uma política ou programa; mas também de processos, que qualifique decisões, resultados e impactos.

Os dados sobre o sistema penitenciário são indicadores complexos que merecem atenção, tanto no aspecto conceitual, quanto na metodologia a ser empregada para obtê-los. Ao mesmo tempo, também se reconhece hoje que a reincidência não é ocasionada simplesmente por questões internas inerentes ao sistema penitenciário, mas também por fatores externos inerentes ao ambiente social, político, econômico e cultural em que o apenado vive.

Além disso, a reincidência não é o único indicador do sucesso ou fracasso da educação ou do trabalho no cárcere. No caso da educação, particularmente vai além da simples aquisição de conhecimentos e de garantia de direitos constitucionais. É perspectiva de mudança de vida, autoestima e outras competências e habilidades para a vida tanto individual quanto social.

Conforme identificado nos resultados da pesquisa, embora veja como positivo o papel da educação e do trabalho na política de reinserção social, defendo que não se pode simplesmente implementá-los para este fim, mas, principalmente, que sejam garantidos como direitos elementares dos privados de liberdade como pessoas humanas. É importante que se compreenda que a educação e o trabalho são fundamentais para o desenvolvimento humano, inclusive para a sua socialização.

Assim, além da reincidência, também considero importantes indicadores para avaliar os sistemas de privação de liberdade: o número de fugas e evasões, rebeliões, motins; de mortes intramuros, principalmente pelas ocasionadas por fatores vinculados à violência $\mathrm{e}$ por negligência institucional; a quantidade de atendimentos biopsicossociais realizados pelos técnicos do sistema; a quantidade de atividades ou a carga horária destinadas para realização de atividades educacionais, culturais, esportivas, profissionalizantes e de lazer pelos internos e as efetivamente cumpridas.

Diante de estudos desenvolvidos na área de políticas públicas e gestão da segurança pública, acreditase que não é por falta de recursos financeiros que o sistema penitenciário se encontra neste estágio de degradação, mas sim pela falta de institucionalização de procedimentos e concepções políticas que otimizem a utilização desses recursos, valorizem a atuação técnica desburocratizada e humana e, principalmente, privilegiem a condição humana sobre todas as coisas.

No campo da educação, por exemplo, é fundamental que se perceba que não é só com a criação de novas escolas, principalmente associadas ao ensino profissional, que resolveremos o problema da educação 
para jovens e adultos privados de liberdade. É necessária uma concepção educacional que valorize e ajude a desenvolver potencialidades e competências; que favoreça a mobilidade social dos internos; que não os deixem sentir-se paralisados diante dos obstáculos que serão encontrados na relação social.

Em suma, deve-se investir na criação de uma escola para os sistemas de privação de liberdade com uma política de educação que privilegie, a qualquer custo, a busca pela formação de um cidadão consciente da sua realidade social. O Ministério da Justiça deve assumir a educação como uma das políticas de reinserção social e, em articulação com os Ministérios da Educação, da Saúde, da Cultura etc., definir as diretrizes nacionais para o "tratamento penitenciário", visando à construção coletiva de uma política pública voltada à alfabetização e à elevação de escolaridade ${ }^{20}$ da população privada ou restrita de liberdade e egressa no contexto das políticas de educação de jovens e adultos.

Já no campo das atividades laborativas, que elas estejam fundamentadas no que determina a Lei de Execução Penal: que tenham a finalidade educativa e não simplesmente de produção de bens e serviços. E principalmente que respeitem as características dos apenados e dos seus regimes de sentença (aberto, semiaberto e fechado) na implementação de uma proposta político-pedagógica de execução penal, fortalecendo os seus reais objetivos.

Neste sentido, a política de execução penal precisa levar em consideração, por exemplo, o seu público-alvo e as características do ambiente prisional de acordo com o regime do sentenciado, adequando-se o tipo de punição e a instituição correcional aos objetivos da sentença.

Ciente de que sem a participação efetiva da sociedade as políticas públicas muitas vezes estão fadadas ao fracasso, acredito que somente se avançará em uma

${ }^{20}$ A perspectiva aqui defendida está centrada na garantia de ampliação do "capital cultural" e não simplesmente da certificação obtida por meio de exames supletivos e, consequentemente, da obtenção de dados estatísticos que apresentem uma relativa melhora nos índices educacionais brasileiros. política de execução penal que atenda os seus reais anseios, principalmente que vislumbre a reinserção social do infrator, com a participação da sociedade civil organizada. Assim, torna-se fundamental que se estimule a criação de conselhos da comunidade em todas as Varas de Execuções Penais, como já previsto na Lei de Execuções Penais, com o objetivo de acompanhar a execução das políticas em cada estado; que, conforme sugerido por Alvino A. de Sá (2007, p. 117-120), as Comissões Técnicas de Classificação também se empenhem na promoção de uma integração cárcere-sociedade; que se invista na implementação de Programas de Informações e Debates, em Programas de Reencontro e Reconciliação preso-vítima-sociedade e na efetiva participação do preso na prestação de serviços à comunidade.

Em síntese, diante das questões explicitadas na pesquisa, acredito que efetivamente conseguiremos avanços consistentes na política de execução penal se:

1) o Governo Federal, por intermédio do Ministério da Justiça (Departamento Penitenciário Nacional), investir na criação e implementação de um Plano Nacional de Execução Penal que se desdobre em Planos Estaduais de Execução Penal;

2) diante dos seus Planos Estaduais, cada estado da federação criar e implementar uma Projeto Político Institucional para a Execução Penal, justificando as suas ações para o seu sistema penitenciário dentro de uma Proposta Política de Tratamento Penitenciário, desdobrando-se em Projetos Político-pedagógicos para cada unidade penal, levando-se em consideração sua realidade concreta (regime, clientela, localização geográfica etc.);

3) ciente de todas as implicações políticas, administrativas e financeiras que envolvem o tema, e percebendo que este será um dos principais avanços no reordenamento da política de execução penal, realizar-se a implementação de uma proposta de um Plano Individual de Atendimento (PIA) para o interno penitenciário que o oriente na execução da sua pena, conforme 
hoje previsto na política socioeducativa brasileira e também na Lei de Execuções Penais;

4) compreendendo que os vínculos familiares, afetivos e sociais são sólidas bases para afastar os condenados da delinquência, ou seja, evitar a reincidência criminal, conforme já previsto na área socioeducativa, o sistema carcerário deverá investir na implementação de um Plano Nacional de Convivência Familiar e Comunitário para a política de execução penal, primando-se por diretrizes e políticas que estreitem os laços familiares e comunitários com os apenados, principalmente ampliando as perspectivas de efetivamente se "mediar os possíveis conflitos" existentes. O Plano para o sistema penitenciário, em linhas gerais, deve representar um importante instrumento para mobilização nacional e suas diretrizes devem transformar-se em ações concretas e articuladas de responsabilidade do Estado e dos diversos atores sociais, assumindo o compromisso pela promoção, proteção e defesa dos direitos dos apenados à convivência familiar e comunitária. Neste sentido, com certeza se vislumbrará um maior sucesso quanto à reinserção social dos apenados à sociedade.

Concluindo, diante do exposto, defendo que necessitamos imediatamente de uma reavaliação da legislação penal vigente que atenda a realidade do sistema penitenciário contemporâneo, que retira do seio social uma grande massa de jovens economicamente ativos, ${ }^{21}$ excluindo-os socialmente e segregando-os política e economicamente dos benefícios sociais. Possibilitar que o interno penitenciário possa remir pela educação é muito pouco para uma proposta de integração social;

${ }^{21}$ Estudos sobre o perfil do interno penitenciário brasileiro evidenciam que são em sua maioria: $75,16 \%$ jovens entre 18 a 34 anos - idade economicamente produtiva; $95,6 \%$ do sexo masculino; $55,61 \%$ pretos e pardos, com uma escolaridade deficiente $(64,6 \%$ não completaram o ensino fundamental) e oriundos de grupos menos favorecidos da população (Brasil, 2008). é necessário que se cobre do poder público uma total reforma na legislação penal e, consequentemente, na política de execução penal, promovendo um verdadeiro "reordenamento institucional". É preciso investir radicalmente em uma política de capacitação dos servidores que atuam em espaços de privação de liberdade, envolvendo o poder público, universidades, centros de pesquisas e organizações da sociedade civil.

Sem ter a pretensão de colocar um ponto final no debate, espero que este artigo venha a contribuir com a referida discussão, possibilitando a ampliação da reflexão, bem como fornecendo subsídio para posteriores desdobramentos. Enquanto não houver uma definição política do papel a ser desempenhado pela política de execução penal e pelas medidas socioeducativas na sociedade contemporânea, temo que se acredite ser inútil investir qualquer recurso nessa direção, pois sem um projeto político para o setor é possível que se assuma a ideia de estarmos literalmente "jogando dinheiro fora".

\section{Referências bibliográficas}

ALFABETIZAÇÃO e Cidadania: revista de educação de jovens e adultos. Brasília: RAAAB, UNESCO, Governo Japonês, 2006.

BARATA, Alessandro. Criminologia Crítica e Crítica do Direito Penal: Introdução à Sociologia do Direito Penal. Rio de Janeiro: Revan;ICC, 2003.

BECCARIA, Cesare. Dos delitos e das penas. São Paulo: Martin Claret, 2000.

BECKER, Howard. Uma teoria da ação coletiva. Rio de Janeiro: Jorge Zahar, 1977.

BENTHAM, Jeremy. O panóptico. Belo Horizonte: Autêntica, 2000.

BRASIL, Ministério da Justiça, Departamento Penitenciário Nacional. Sintese das Ações do Departamento Penitenciário Nacional: ano 2007 e metas para 2008. Brasília: DEPEN, 2008.

BITTAR, Walter. A criminologia no século XXI. Rio de Janeiro: Lumen Juris \& IBCCRIM, 2007.

BREITMAN, Miriam. I. Rodrigues. Mulheres, crimes e prisão: o significado da ação pedagógica em uma instituição carcerária feminina. 1989. Dissertação (Mestrado em Educação) - Faculdade de Educação, Universidade Federal do Rio Grande do Sul, Porto Alegre, 1989. 
O impacto da educação e do trabalho como programas de reinserção social na política de execução penal do Rio de Janeiro

CHRISTIE, Nils. La industria del control del delito: la nueva forma del holocausto?. Buenos Aires: Editores del Puerto, 1993.

Uma sensata cantidad de delito. Buenos Aires: Editores

del Puerto, 2004.

FOUCAULT, Michel. Vigiar e punir: nascimento da prisão. Petrópolis: Vozes, 2000.

FRADE, Laura. O que o Congresso Nacional brasileiro pensa sobre a criminalidade. 2007. Tese (Doutorado) - Universidade de Brasília, Brasília, 2007.

GARLAND, David. As contradições da "sociedade punitiva": o caso britânico. Revista de Sociologia e Política. Curitiba, n.13, p. 59-80, nov. 1999.

. La cultura del control: crimen y orden social en la sociedad contemporánea. Barcelona: GEDISA Editorial, 2005.

. Punishment and Modern Society: a study in social theory. Oxford: Oxford University Press, 1990.

GOFFMAN, Erving. Estigma: Nota sobre a manipulação da identidade deteriorada. Rio de Janeiro: LTC, 1988.

Manicômios, prisões e conventos. São Paulo: Perspectiva, 1961.

JULIÃO, Elionaldo Fernandes. Política Pública de Educação Penitenciária: contribuição para o diagnóstico da experiência do Rio de Janeiro. 2003. Dissertação (Mestrado) - Departamento de Educação, PUC, Rio de Janeiro, 2003 (orientada por Rosália Duarte).

. A ressocialização através do estudo e do trabalho no sistema penitenciário brasileiro. 2009. Tese (Doutorado) - Programa de Pós-graduação em Ciências Sociais da UERJ, Rio de Janeiro, 2009 (orientada por Ignácio Cano).

MÉSZÁROS, István. A educação para além do Capital. São Paulo: Boitempo, 2005.

ONOFRE, Elenice Maria Cammarosano (Org.). Educação escolar entre as grades. São Carlos: EDUFSCAR, 2007.

ONU \& UNESCO. La educación básica em los establecimientos penitenciarios. EUA; Viena: 1994.

PAIVA, Jane. Os sentidos do direito à educação para jovens e adultos. Petrópolis: DP et al. Rio de Janeiro: FAPERJ, 2009.

PERROT, Michelle. Os excluídos da história: operários, mulheres e prisioneiros. Rio de Janeiro: Paz e Terra, 1988.

REGRAS Mínimas para o Tratamento do Preso no Brasil. Brasília: Conselho Nacional de Política Criminal e Penitenciária, 1995.
SÁ, Alvino Augusto. Os dilemas de prioridades e de paradigmas nas políticas de segurança dos cárceres na formação dos agentes penitenciários. In: BITTAR, Walter Barbosa (Org.). A criminologia no século XXI. Rio de Janeiro: Lumen Júris; IBCCRIM, 2007, p. 1-5.

SOARES, Leôncio. Educação de jovens e adultos. Rio de Janeiro: DP\&A, 2002.

THOMPSON, Augusto. O futuro da criminologia. In: BITTAR, Walter. A Criminologia no Século XXI. Rio de Janeiro: Lumen Juris \& IBCCRIM, 2007.

. A questão da penitenciária. 2. ed. Rio de Janeiro: Forense, 1980.

UNESCO. Educación en prisiones en Latinoamérica: derechos, libertad y ciudadanía. Brasília: UNESCO, 2008.

WACQUANT, Loïc Os condenados da cidade: estudo sobre marginalidade avançada. Rio de Janeiro: Revan; FASE, $2001 \mathrm{~b}$.

. As prisões da miséria. Rio de Janeiro: Jorge Zahar, 2001a.

. Punir os pobres: a nova gestão da miséria nos Estados Unidos. Rio de Janeiro: Instituto Carioca de Criminologia; Editora Freitas Bastos, 2001c.

ZAFFARONI, Eugenio Raúl. Em busca das penas perdidas: a perda de legitimidade do sistema penal. Rio de Janeiro: Revan, 2001.

ELIONALDO FERNANDES JULIÃO, doutor em ciências sociais pela Universidade do Estado do Rio de Janeiro, é professor no curso de pedagogia da Universidade Federal Fluminense, no Instituto de Educação de Angra dos Reis. Principais publicações: Politica pública de educação penitenciária: contribuição para o diagnóstico da experiência do Rio de Janeiro (Dissertação de Mestrado em Educação, Departamento de Educação da Pontifícia Universidade Católica do Rio de Janeiro, Rio de Janeiro, 2003); Educação e trabalho como propostas políticas de execução penal (Alfabetização e Cidadania: revista de educação de jovens e adultos, Brasília, RAAAB, UNESCO, Governo Japonês, 2006); A ressocialização através do estudo e do trabalho no sistema penitenciário brasileiro (Tese de Doutorado em Ciências Sociais, Universidade do Estado do Rio de Janeiro, 2009).E-mail: elionaldoj@yahoo.com.br.

Recebido em agosto de 2010 Aprovado em outubro de 2010 
Elionaldo Fernandes Julião

O impacto da educação e do trabalho como programas de reinserção social na política de execução penal do Rio de Janeiro Considerando-se que hoje, no Brasil, não há informações consistentes sobre a reincidência entre egressos penitenciários que, sem qualquer fundamentação empírica, é identificada como alta no país, este artigo tem como objetivos: compreender como vêm funcionando os programas educativos e laborativos no sistema penitenciário brasileiro, qual a percepção dos diversos agentes operadores da execução penal quanto aos programas de ressocialização, e qual o impacto efetivo da educação e do trabalho na ressocialização dos detentos. Pretendeu-se verificar se realmente os programas de ressocialização de cunho educacional e laborativo interferem diretamente na reinserção social do apenado, bem como qual seu efetivo impacto na execução penal.

Palavras-chave: privação de liberdade; sistema penitenciário; ressocialização; programas de reinserção social; educação e trabalho; educação de jovens e adultos

The impact of education and work as programmes for social reinsertion on the policy of penal execution in Rio de Janeiro Considering that today, in Brazil, there is no consistent information 
on recidivism among ex-prisoners, which, without any empirical basis, is considered high, the aims of this article are: to understand how the education and work programmes function in the Brazilian penitentiary system, how the diverse agents of penal execution perceive the re-socialization programmes and how effective is the impact of education and work on the re-socialization of prisoners. The intention was to verify if the resocialization programmes based on work and education really interfere directly in the social reinsertion of the convict, as well as what its effective impact is on penal execution.

Key words: privation of liberty; penitentiary system; re-socialization; programmes for social reinsertion; education and work; youth and adult education

\section{El impacto de la educación y} del trabajo como programas de reintegración social en la política de ejecución penal en Rio de Janeiro

Considerándose que hoy, en

Brasil, no se posee informaciones consistentes sobre la reincidencia entre egresos penitenciarios que, sin cualquier fundamentación empírica, es identificada como alta en el país, este articulo tiene como objetivos: comprender como vienen funcionando los programas educativos y laborables en el sistema penitenciario brasileño, cual la percepción de los diversos agentes operadores de la ejecución penal cuanto a los programas de resocialización de los presos. Se pretendió verificar si realmente los programas de resocialización de carácter educacional y laboratorio, interfieren directamente en la reintegración social del preso, bien como cual es su efectivo impacto en la ejecución penal.

Palabras clave: privación de la libertad; sistema penitenciario; resocialización; programas de reintregración social; educación y trabajo; educación de jóvenes y adultos 